\title{
(6) OPEN ACCESS \\ The feasibility of using dose-banded syringes to improve the safety and availability of patient-controlled opioid analgesic infusions in children
}

\author{
Asia N Rashed, ${ }^{1,2}$ Cate Whittlesea, ${ }^{3}$ Ben Forbes, ${ }^{1}$ Stephen Tomlin ${ }^{1,2}$
}

\begin{abstract}
${ }^{1}$ Institute of Pharmaceutical Science, King's College London, King's Health Partners, London, UK ${ }^{2}$ Pharmacy Department, Evelina London Children's Hospital, Guy's \& St Thomas' NHS Foundation Trust, King's Health Partners, London, UK ${ }^{3}$ School of Medicine, Pharmacy and Health, Durham University, Durham, UK
\end{abstract}

\section{Correspondence to} Stephen Tomlin, Pharmacy Department, Evelina London Children's Hospital, Guy's \& St Thomas' NHS Foundation Trust, London SE1 7EH, UK ; Stephen.Tomlin@gstt.nhs.uk

Received 6 January 2014 Revised 17 June 2014 Accepted 2 July 2014 Published Online First 24 July 2014

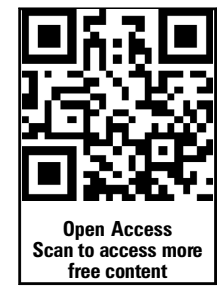

CrossMark

To cite: Rashed AN Whittlesea C, Forbes B, et al. Eur I Hosp Pharm 2014;21:306-308.

\section{OPIOID ANALGESIA IN CHILDREN}

Opioid infusions are essential therapy for children in severe pain. Patient controlled analgesia (PCA) is an attractive treatment option because of the multiple benefits it provides: immediate and effective pain relief, titration of analgesia and empowerment of the patient (or nurse) to have a degree of control over their pain which helps to retain autonomy and decrease anxiety. However, opioid infusions for children carry a high risk of medication error. Risks include the complexity in calculating dosages, the manipulation of small volumes to prepare individual infusions and the necessity to deliver the infusion with precision at low flow rates (down to $0.1 \mathrm{~mL} / \mathrm{h}$ ). During PCA additional boluses on top of the baseline infusion rate add to the pharmaceutical and therapeutic complexity. The severe side effects of opioids, including hypoventilation, hypotension and sedation, exacerbate the risk and raise great concern in hospitals, plus limiting the use of PCA in community and hospice settings.

At present there is no international standard practice or guideline on the way that PCA is administered. This commentary highlights problems with current practices of preparing and administering PCA in hospitalised children in the UK. Additionally, we advocate a system management approach which we are piloting to address the problems of opioid-based PCA for children in a large (200-bed) hospital, the Evelina London Children's Hospital, in the hope of developing safer practices for the delivery of opioid analgesia.

\section{OPIOID INFUSIONS IN PAEDIATRIC PHARMACY}

Intravenous infusions are an important means of administering therapy, yet the technical process is complex with multiple error-prone steps. The errors associated with preparing and administering intravenous infusions in paediatrics (eg, low volume at low flow rate) make drug delivery by infusion a particularly high risk, ${ }^{1}$ but continuous infusions of opioid are crucial to achieve effective analgesia and avoid uncontrolled pain in neonates and children with conditions such as sickle cell disease and post surgery. Administering infusions to children requires complex dose calculations, infusion rate adjustments and often requires several manipulations of injectable medicines to obtain the final 'ready to use' infusion solution. Errors involving the wrong diluent or volume/dose or wrong infusion rate are common, with incidence rates between $1.6 \%$ and $91.7 \%$ reported. $^{2-6}$ Tenfold or greater dose errors have been reported through misplacement of the decimal point. For example a premature baby died $28 \mathrm{~h}$ after birth when a junior doctor prescribed $15 \mathrm{mg}$ of intravenous morphine instead of $0.15 \mathrm{mg}$, resulting in administration of a 100 times overdose. ${ }^{7}$ We consider that the risk of error for potent medicines such as morphine under current practices is not acceptable.

The preparation of individually manufactured syringes presents a significant source of error in opioid infusions. This problem was quantified in a study by Parshuram et $a l^{8}$ in which discrepancies were measured between prescribed and delivered concentrations of opioid infusions in neonatal and paediatric intensive care units. The study found that $6 \%$ of morphine infusions (prepared at ward level) had a twofold or greater concentration error. A second study identified a high rate of errors during drug-volume calculations or introduced by rounding off of volume and dose, that is, rounding the calculation to the nearest measurable volume (eg, $2.46-2.5 \mathrm{~mL}$ ) to match syringe graduations, during the preparation of morphine syringes. ${ }^{4}$ Of the 464 morphine infusions prepared during the course of the study, $34.7 \%$ had a concentration error (deviation of $10 \%$ or greater from expected concentration).

While error introduced by rounding may appear minimal initially, it can be compounded by inaccuracies during the multiple-step infusion preparation process. A typical example (box 1) highlights the variability arising from the manufacturing method and the scope for calculation error. However, it has to be acknowledged that practices vary and therefore the source and magnitude of variance or error may differ.

Standardisation of morphine concentrations for infusions and batch manufacture to pharmacopoeial standards of accuracy removes individualised preparation as a source of error. It has been reported that $21 \%$ of errors associated with paediatric infusions can be avoided if the reconstitution and dilution steps are replaced by the use of preprepared syringes. ${ }^{9}$ However, it has to be acknowledged that it is essential to agree to one set of standard solutions in order to move towards batch manufacture and consistent working across the profession.

Unlike adult practice where all patients receive a single standard adult dose, children's doses are calculated on the basis of their weight, which may range from $0.5 \mathrm{~kg}$ to $100 \mathrm{~kg}$ (a difference of 200 times). 
Box 1 An example of inaccuracies arising in the preparation of a paediatric morphine infusion

If a 24 week baby of $470 \mathrm{~g}$ requires morphine at a dose of $10 \mu \mathrm{g} /$ $\mathrm{kg} / \mathrm{h}$ this can be achieved by preparing ' $(5 \times$ weight $(\mathrm{g})) / 1000 \mathrm{mg}$ in $50 \mathrm{~mL}$ ' then administering at $0.1 \mathrm{~mL} / \mathrm{h}$ to provide the target dose of $10 \mu \mathrm{g} / \mathrm{kg} / \mathrm{h}$. To manufacture the infusion, the dose of morphine is $(5 \times 470) / 1000=2.35 \mathrm{mg}$, which is to be diluted up to $50 \mathrm{~mL}$. Morphine sulfate is available as a $10 \mathrm{mg} / \mathrm{mL}$ injection, thus the $2.35 \mathrm{mg}$ dose is in $0.235 \mathrm{~mL}$ volume. As the syringes are only accurate to $0.1 \mathrm{~mL}$, a volume of $0.2 \mathrm{~mL}(2 \mathrm{mg})$ will be placed in $50 \mathrm{ml}$ (should be $49.8 \mathrm{~mL}$, but a $50-\mathrm{mL}$ syringe is not accurate enough). So, the prepared product, $2 \mathrm{mg}$ in $50.2 \mathrm{~mL}$, has a concentration of $0.0398 \mathrm{mg} / \mathrm{mL}$ which when administered at $0.1 \mathrm{~mL} / \mathrm{h}$ provides a dose of $3.98 \mu \mathrm{g} / \mathrm{h}$. This is a significant deviation from the prescribed dose of $4.7 \mu \mathrm{g} / \mathrm{h}(10 \mu \mathrm{g} / \mathrm{kg} / \mathrm{h})$.

In this example there is $15 \%$ variance based on the calculation, plus the potential for 10 -fold errors and the likelihood of inaccuracy of measurement during preparation.

This means that more complex calculations are required to produce paediatric preparations. Current practice in UK and European hospitals is to prepare syringes individually for children using a system called the 'rule of 6' (box 2) to calculate the infusion rate for paediatric drug infusions which are prescribed in micrograms $(\mu \mathrm{g})$ per kilogram per minute. ${ }^{9}$

\section{LOCAL EXPERIENCE OF ERROR WITH MORPHINE INFUSIONS}

Studies by Rashed et al conducted on paediatric wards in hospitals in European and non-European countries including; Australia, Germany, UK, Malaysia, China (Hong Kong) and Saudi Arabia; in 2008-2009 and 2010 identified morphine as: (A) the drug associated with the highest number of medication errors, (B) more frequently prescribed for paediatric patients in UK compared with other countries. ${ }^{10-12}$ Similar findings have been reported by others. ${ }^{13}$

A project was conducted in the paediatric intensive care unit at Evelina London Children's Hospital in the UK to convert morphine infusions from the named patient model (using the rule of 6), to dose-banded standard concentrations of morphine prepared by pharmacy. The standard concentrations were prepared in $50 \mathrm{~mL}$ volumes as quality assured prefilled syringes at the pharmacy manufacturing unit at Guy's and St Thomas NHS Foundation Trust using batch manufacture with quality control to verify that the concentrations are within the British Pharmacopoeia ${ }^{14}$ limits for morphine sulfate injection, that is, $\pm 7.5 \%$ of the label strength. Safety pumps with accurate display of low flow rates and programmable software features including lockout intervals, limits on the total dosage in a set time interval and patient administered dosing were used to deliver the

\section{Box 2 The Rule of Six}

The formula is described as: $6 \times$ patient's weight $(\mathrm{kg})$ equals the amount of drug in milligrams that should be added to $100 \mathrm{~mL}$ of solution. When administered at $1 \mathrm{~mL} / \mathrm{h}$ will give an infusion rate of $1 \mu \mathrm{g} / \mathrm{kg} / \mathrm{min}$ (or $60 \mu \mathrm{g} / \mathrm{kg} / \mathrm{h}$ ). ${ }^{9}$ infusions. A review of the hospital incident reporting system 2 years post implementation showed that errors of wrong diluent and wrong dose prepared were entirely eliminated (unpublished data). However, there was no significant change in the reported error frequency over 2 years preimplementation and postimplementation. While the low reporting makes this data clinically insignificant, it is unquestionable that the standardised syringes are far more accurate (quality assured certified) compared with the ward-made syringes, suggesting a much improved system. In another study at the same hospital the accuracy of morphine infusions prepared for neonates in the neonatal intensive care unit was measured. It was found that $19.2 \%$ of morphine infusions prepared by nurses in the neonatal intensive care unit were outside the British Pharmacopoeia ${ }^{14}$ concentration limits for morphine sulfate injection, with more than $20 \%$ deviation in concentrations identified. The study also found that the smaller the volume of morphine injection required to prepare the infusions, the greater the magnitude and frequency of deviation from the intended concentration. ${ }^{15}$

\section{STANDARDISATION AS A SYSTEM MANAGEMENT APPROACH TO SAFER PCA}

The studies described above establish the nature and source of some of the errors associated with morphine therapy. This laid the ground work for our current initiative to develop a system management approach to eliminate the risk of medication error in the most challenging setting: patient-controlled analgesia for children using morphine. Our proposed solution is a system to minimise complex calculations and individualised medicine manufacture at the point of administration by providing standard dose-banded concentrations of morphine infusion for PCA administration using preprogrammed safety pumps for hospitalised paediatric patients. Implementing the new system of morphine standard concentrations is taking place in three phases. ${ }^{16}$

The implementation of a standardised dose-banded infusion system for morphine delivery by patient-controlled analgesia for children has not to our knowledge, been implemented anywhere in the world to date. Preprepared syringes containing standard concentrations of intravenous infusions have been introduced sporadically in the UK and internationally over the last few years. ${ }^{15}{ }^{17-19}$ A study in children determined that the number of reported errors associated with continuous medication infusions dropped by $73 \%$ after implementation of standard drug concentrations solutions administered using advanced safety pumps with inbuilt drug libraries and default settings to facilitate selection of correct medication and dose. ${ }^{18}$ Standardising infusion concentrations is recognised internationally as an important step in improving patient safety. ${ }^{20}$ A UK Department of Health commissioned study concluded that the introduction of standardised dose-banded syringes, manufactured by centralised intravenous additive services, used with a preprogrammed safety pump would avoid the most common dosing errors in neonates and paediatrics. ${ }^{17}$ However, challenges such as establishing dose bands, availability of sufficiently accurate, programmable pumps, capacity to manufacture or quality assure the injections, and availability of secure and sufficient storage have prevented the implementation of these recommendations to date.

To avoid error in the preparation and delivery of morphine to children by infusion we are piloting standardised quality assured prefilled syringes of dose-banded infusions (at three concentrations) for administration via preprogrammed safety pumps (figure 1). ${ }^{21}$ The lockable pumps are capable of delivering individualised PCA for hospitalised paediatric patients in intensive 


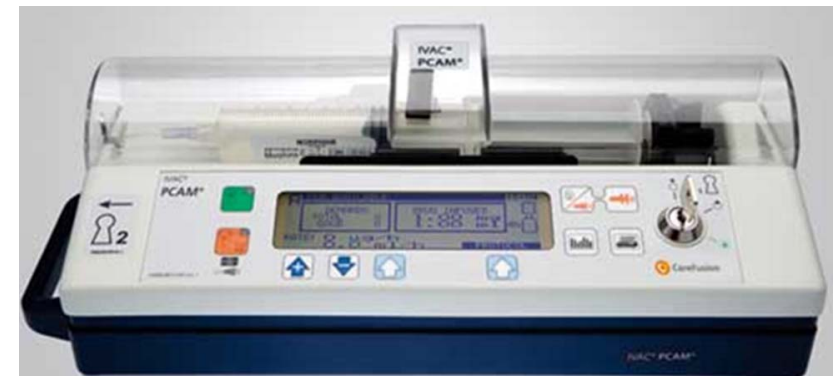

Figure 1 Syringe pump (IVAC PCAM) ${ }^{21}$ currently used in Evelina London Children's Hospital.

and non-intensive areas with accuracy and precision. Preprogramming of the pump with the standard strength removes the possibility of miscalculating the administration rate, which will be set according to the patient's weight. Use of the wrong strength infusion for the programme is a potential error and could be eliminated using bar coding, which is an option that is being explored. Standardised infusions were banded based on child's weight $(<4-\geq 20 \mathrm{~kg})$ after considering the rate of delivery that would be necessary for infusions with morphine concentrations of $1-50 \mathrm{mg}$ in $50 \mathrm{~mL}$. The three identified standard morphine concentrations will be implemented slowly across different units within the hospital to allow for evaluation and review of the established bands in practice, before full roll-out across the hospital. These standard infusions will be administered as per the current N/PCA protocols used at the Trust; for example nurse-controlled analgesia (NCA) protocol runs at an infusion rate of $20 \mu \mathrm{g} / \mathrm{kg} / \mathrm{h}$ with bolus dose of $10 \mu \mathrm{g} / \mathrm{kg}$.

Even at the extremes of the weight range, the dose-banded system will deliver the prescribed dose. With the 'rule of 6 ' method however, although inaccurate infusion preparation may be compensated for by titrating the N/PCA according to response, it is still an unacceptable method of practice and will influence the clinical judgement about a child's pain when syringes are changed. For example, a syringe that has a concentration that is $20 \%$ too high changed to a syringe that has a concentration $30 \%$ too low would lead to an observation that a child's pain is significantly increasing.

We hope that the implementation of the standard morphine concentrations for PCA use in children will result in demonstrable risk reduction compared with current practice. Furthermore, the system is anticipated to provide welcome economic savings, simplicity of use and efficiencies in staff time. Ultimately the aim is to make this vital but currently high risk therapy less risky and thus more widely available, that is, extending the use to environments such as ambulatory care and community settings where cost, complexity and risk currently restrict the access of children to PCA.

Contributors All authors were involved in the project concept and design. ANR wrote the first draft of the manuscript. ST, BF and CW revised the manuscript and approved the final version.

Funding This project is part of the Health Foundation's SHINE 2012 programme, reference number 551. The Health Foundation is an independent charity working to continuously improve the quality of healthcare in the UK.

Competing interests ANR is funded by the Health Foundation.
Provenance and peer review Not commissioned; externally peer reviewed.

Open Access This is an Open Access article distributed in accordance with the Creative Commons Attribution Non Commercial (CC BY-NC 3.0) license, which permits others to distribute, remix, adapt, build upon this work non-commercially, and license their derivative works on different terms, provided the original work is properly cited and the use is non-commercial. See: http://creativecommons.org/ licenses/by-nc/3.0/

\section{REFERENCES}

1 Ghaleb MA, Barber N, Franklin BD, et al. The incidence and nature of prescribing and medication administration errors in paediatric inpatients. Arch Dis Child 2010;95:113-18.

2 Wong IC, Wong LY, Cranswick NE. Minimising medication errors in children. Arch Dis Child 2009;94:161-4.

3 National Patient Safety Agency (NPSA). Intravenous morphine administration on neonatal units: Signal. 25th March 2011, http://www.nrls.npsa.nhs.uk/resources/ patient-safety-topics/medication-safety/?entryid45=130181 (accessed $21 \mathrm{Mar}$ 2014).

4 Parshuram CS, To T, Seto W, et al. Systematic evaluation of errors occurring during the preparation of intravenous medication. CMAJ 2008;178:42-8.

5 Taxis K, Barber N. Ethnographic study of incidence and severity of intravenous drug errors. BMJ 2003;326:684.

6 Westbrook Jl, Rob MI, Woods A, et al. Errors in the administration of intravenous medications in hospital and the role of correct procedures and nurse experience. BMJ Qual Saf 2011;20:1027-34.

7 Jacqz-Aigrain E, Choonara I Paediatric clinical pharmacology. Chapter 3: medication errors by Cousins DH. New York, London: FontisMedia SA and Taylor \& Francis Group, 2006:254.

8 Parshuram CS, Ng GY, Ho TK, et al. Discrepancies between ordered and delivered concentrations of opiate infusions in critical care. Crit Care Med 2003;31:2483-87.

9 Mcleroy PA. The rule of six: calculating intravenous infusions in a pediatric crisis situation. Hosp Pharm 2004;29:939-40.

10 Rashed AN, Wong ICK, Cranswick N, et al. Adverse Drug Reactions in ChildrenInternational Surveillance and Evaluation (ADVISE): a multicentre cohort study. Drug Saf 2012;35:481-94.

11 Rashed AN, Wong ICK, Cranswick N, et al. Risk factors associated with adverse drug reactions in hospitalised children: international multicentre study. Eur J Clin Pharmacol 2012;68:801-10.

12 Rashed AN, Neubert A, Tomlin S, et al. Epidemiology and potential associated risk factors of drug-related problems in hospitalised children in United Kingdom and Saudi Arabia. Eur J Clin Pharmacol 2012;68:1657-66.

13 Neubert A, Verhamme K, Murray ML, et al. The prescribing of analgesics and non-steroidal anti-inflammatory drugs in paediatric primary care in the UK, Italy and the Netherlands. Pharmacol Res 2010;62:243-8.

14 Department of Health. British pharmacopoeia: morphine sulphate injection. London: TSO, 2011.

15 Aguado-Lorenzo V, Weeks K, Tunstell P, et al. Accuracy of the concentration of morphine infusions prepared for patients in a neonatal intensive care unit. Arch Dis Child 2013;98:975-9.

16 Shine 2012, Evelin Children's Hospital, Health Foundation. Safe, patient controlled intravenous pain relief in children. http://www.health.org.uk/areas-of-work/ programmes/shine-twelve/related-projects/evelina-children-s-hospital/the-project/ (accessed 27 Mar 2014).

17 Co-operative of Safety of Medicines in Children (COSMIC): Scoping study to identify and analyse interventions used to reduce errors in calculation of paediatric drug doses. Report to the Patient Safety Research Program, Department October 2007. http://www.birmingham.ac.uk/Documents/college-mds/haps/projects/cfhep/psrp/ finalreports/PS026COSMICFinalReport.pdf (accessed 21 Mar 2014).

18 Larsen GY, Parker HB, Cash J, et al. Standard drug concentrations and smart-pump technology reduce continuous-medication-infusion errors in paediatric patients. Paediatrics 2005;116:e21-5.

19 Irwin D, Vaillancourt R, Dalgleish D, et al. Gaboury I. Standard concentrations of high-alert drug infusions across paediatric acute care. Paediatr Child Health 2008;13:371-6

20 Hilmas $\mathrm{E}$, Sowan $\mathrm{A}$, Gaffoor $\mathrm{M}$, et al. Implementation and evaluation of a comprehensive system to deliver pediatric continuous infusion medications with standardized concentrations. Am J Health Syst Pharm 2010;67:58-69.

21 IVAC@ PCAM® syringe pump. http://www.carefusion.co.uk/medical-products/ infusion/alaris-system/ivac_pcam_syringe_pump.aspx (accessed 30 Dec 2013). 


\section{CORRECTIONS}

Rashed AN, Whittlesea C, Forbes B, et al. The feasibility of using dose-banded syringes to improve the safety and availability of patient-controlled opioid analgesic infusions in children (Eur J Hosp Pharm 2014;21:306-308). This paper should have been published in this Paediatrics themed issue. Unfortunately, during the revision process our submissions system $\mathrm{did}$ not register it as a paper for the themed issue and as a result it was published early, in October's issue. We would like to apologise to the authors for this oversight.

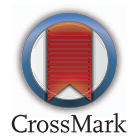

Eur J Hosp Pharm 2014;21:378.

doi:10.1136/ejhpharm-2014-000441corr1 